\title{
Climatic consequences of regional nuclear conflicts
}

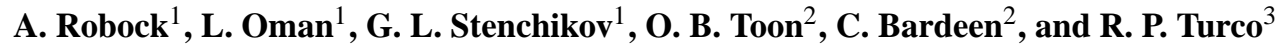 \\ ${ }^{1}$ Department of Environmental Sciences, Rutgers University, New Brunswick, NJ, USA \\ ${ }^{2}$ Department of Atmospheric and Oceanic Sciences and Laboratory for Atmospheric and Space Physics, University of \\ Colorado, Boulder, USA \\ ${ }^{3}$ Department of Atmospheric and Oceanic Sciences, University of California, Los Angeles, USA
}

Received: 15 August 2006 - Published in Atmos. Chem. Phys. Discuss.: 22 November 2006

Revised: 8 March 2007 - Accepted: 2 April 2007 - Published: 19 April 2007

\begin{abstract}
We use a modern climate model and new estimates of smoke generated by fires in contemporary cities to calculate the response of the climate system to a regional nuclear war between emerging third world nuclear powers using 100 Hiroshima-size bombs (less than $0.03 \%$ of the explosive yield of the current global nuclear arsenal) on cities in the subtropics. We find significant cooling and reductions of precipitation lasting years, which would impact the global food supply. The climate changes are large and longlasting because the fuel loadings in modern cities are quite high and the subtropical solar insolation heats the resulting smoke cloud and lofts it into the high stratosphere, where removal mechanisms are slow. While the climate changes are less dramatic than found in previous "nuclear winter" simulations of a massive nuclear exchange between the superpowers, because less smoke is emitted, the changes are more long-lasting because the older models did not adequately represent the stratospheric plume rise.
\end{abstract}

\section{Introduction}

The casualties from the direct effects of blast, radioactivity, and fires resulting from the massive use of nuclear weapons by the superpowers would be so catastrophic that we avoided such a tragedy for the first four decades after the invention of nuclear weapons. The realization, based on research conducted jointly by Western and Soviet scientists (Crutzen and Birks, 1982; Aleksandrov and Stenchikov, 1983; Turco et al., 1983, 1990; Robock, 1984; Pittock et al., 1986; Harwell and Hutchinson, 1986; Sagan and Turco, 1990), that the climatic consequences, and indirect effects of the collapse of society, would be so severe that the ensuing nuclear winter would produce famine for billions of people far from the tar-

Correspondence to: A. Robock

(robock@envsci.rutgers.edu) get zones, may have been an important factor in the end of the arms race between the United States and the Soviet Union (Robock, 1989).

Now the world faces the prospect of many other states developing small nuclear arsenals. Toon et al. (2007a) show that the direct effects of even a relatively small number of nuclear explosions would be a disaster for the region in which they would be used. Here we examine the climatic effects of the smoke produced by the fires that would be ignited by a regional conflict in the subtropics between two countries, each using 50 Hiroshima-size (15 kt) nuclear weapons to attack the other's most populated urban areas. Based on the analysis by Toon et al. (2007a), such a conflict would generate $1-5 \mathrm{Tg}$ of black carbon aerosol particles injected into the upper troposphere, after the initial removal in black rain.

\section{Climate model}

We conducted climate model simulations with a state-of-theart general circulation model, ModelE from the NASA Goddard Institute for Space Studies (Schmidt et al., 2006), which includes a module to calculate the transport and removal of aerosol particles (Koch et al., 2006). The atmospheric model is connected to a full ocean general circulation model with calculated sea ice, thus allowing the ocean to respond quickly at the surface and on yearly time scales in the deeper ocean.

The climate model (with a mixed-layer ocean) does an excellent job of modeling the climatic response to the 1912 Katmai volcanic eruptions (Oman et al., 2005). We have also used this model to simulate the transport and removal of sulfate aerosols from tropical and high-latitude volcanic eruptions (Oman et al., 2006), and have shown that it does a good job of simulating the lifetime and distribution of the volcanic aerosols. In the stratosphere, these aerosols have an e-folding residence time of 12 months in the model, in excellent agreement with observations. The aerosol module (Koch

Published by Copernicus GmbH on behalf of the European Geosciences Union. 
A) Absorption Optical Depth $5 \mathrm{Tg}$ Black Carbon

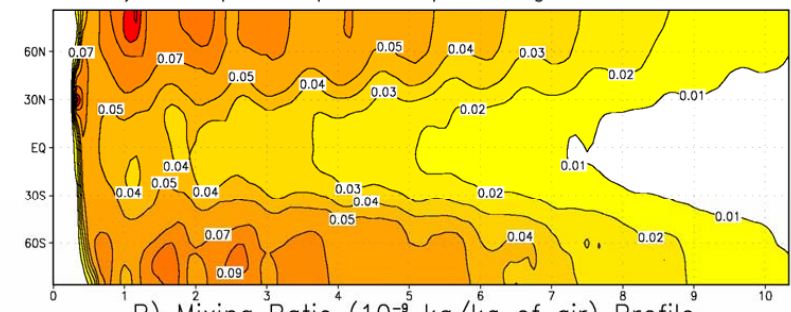

B) Mixing Ratio ${ }^{4}\left(10^{-s^{3}} \mathrm{~kg} / \mathrm{kg}^{6} \text { of }{ }^{3} \text { air }\right)^{\frac{b}{b}}$ Profile

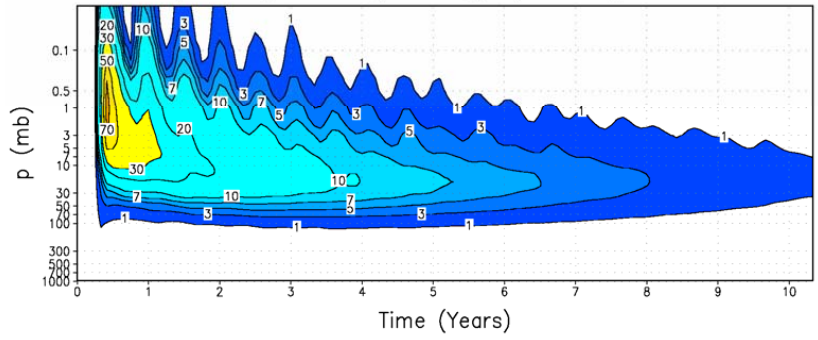

Fig. 1. Horizontal and vertical distributions of smoke for the $5 \mathrm{Tg}$ standard case. (A) Zonal average absorption optical depth, as function of latitude and time. The poleward spread and subsequent loss of smoke over time is clearly seen. (B) Global average vertical distribution of black carbon as a function of time, plotted as mass mixing ratio. The semiannual lofting is due to heating during the solstice in each summer hemisphere (Fig. 2).

et al., 2006) also accounts for black carbon particles, which have an effective radius of $0.1 \mu \mathrm{m}$. At visible wavelengths the black carbon particles have a mass extinction coefficient of $9 \mathrm{~m}^{2} / \mathrm{g}$, a single scattering albedo of 0.31 , and a mass absorption coefficient of $6.21 \mathrm{~m}^{2} / \mathrm{g}$ (also see Toon et al., 2007a).

We run the atmospheric portion of the model at $4^{\circ} \times 5^{\circ}$ latitude-longitude resolution, with 23 vertical layers extending to a model top of $80 \mathrm{~km}$. The coupled oceanic general circulation model (Russell et al., 1995) has 13 layers and also a $4^{\circ} \times 5^{\circ}$ latitude-longitude resolution. In our standard calculation, we inject $5 \mathrm{Tg}$ of black carbon on 15 May into one column of grid boxes at $30^{\circ} \mathrm{N}, 70^{\circ} \mathrm{E}$. We place the black carbon in the model layers that correspond to the upper troposphere (300-150 mb).

We conducted a 30-yr control run with no smoke aerosols and three 10-yr simulations with smoke, starting from arbitrary initial conditions. We present the mean of the ensemble of the three runs, and compare it to the mean of the control run. The differences between ensemble members are small compared to the response, ensuring us that natural, chaotic weather variability is not responsible for the effects we see.

\section{Results}

In the model, the black carbon particles in the aerosol layer are heated by absorption of shortwave radiation. This heating induces vertical motions and the aerosols are lofted to near the top of the stratosphere (Fig. 1),

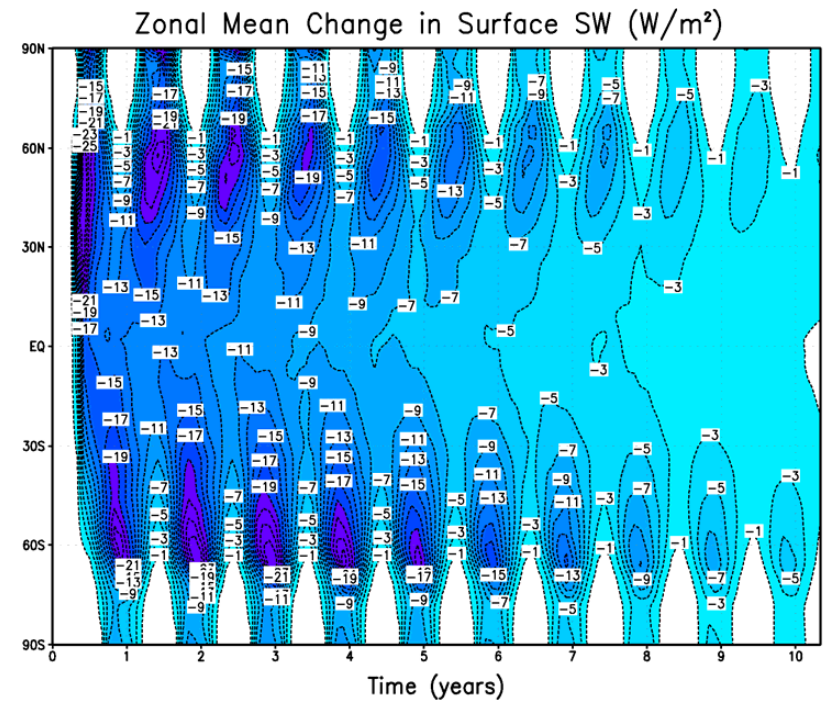

Fig. 2. Zonal mean change in surface shortwave radiation for the $5 \mathrm{Tg}$ standard case. This should be compared to the global average value of $+1.5 \mathrm{~W} / \mathrm{m}^{2}$ for a doubling of atmospheric $\mathrm{CO}_{2}$, or to the maximum value of $-3 \mathrm{~W} / \mathrm{m}^{2}$ for the $1991 \mathrm{Mt}$. Pinatubo volcanic eruption (Kirchner et al., 1999; Fig. 3), the largest of the 20th century.

much higher than is typical of weakly absorbing volcanic sulfate aerosols (Stenchikov et al., 1998). Supplemental Fig. 1 (http://www.atmos-chem-phys.net/7/2003/2007/ acp-7-2003-2007-supplement.zip) shows an animation of the horizontal and vertical spreading of the smoke cloud from one of the ensemble members. As a result, the aerosols have a very long residence time and continue to affect surface climate for more than a decade. The mass e-folding time for the smoke is $6 \mathrm{yr}$, as compared to $1 \mathrm{yr}$ for typical volcanic eruptions (Oman et al., 2006) and 1 week for tropospheric aerosols. After $6 \mathrm{yr}$, the e-folding time is reduced, but is still longer than that of volcanic aerosols. This long aerosol lifetime is different from results found in previous nuclear winter simulations, which either fixed the vertical extent of the aerosols (Turco et al., 1983) or used older-generation climate models with limited vertical resolution and low model tops (Aleksandrov and Stenchikov, 1983; Covey et al., 1984; Malone et al., 1986), artificially limiting the particle lifetimes. In addition, the subtropical latitude of the smoke injections, in the case investigated here, results in more solar heating than in previous nuclear winter scenarios, which considered smoke from the midlatitude Soviet Union, Europe, and the U.S. The lower latitude also ensures that lofting would take place year-round. Therefore the large effects may not be limited to wars that occur in spring and summer, as previously found (Robock, 1984; Covey et al., 1984; Schneider and Thompson, 1988).

The maximum change in global-average surface shortwave radiation is $-15 \mathrm{~W} \mathrm{~m}^{-2}$ (Fig. 2). This negative forcing 


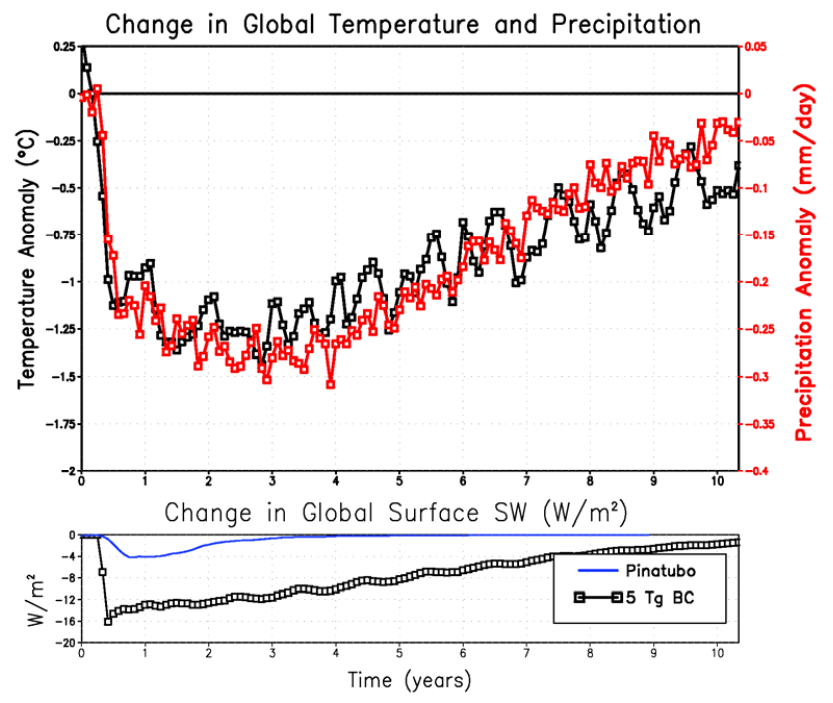

Fig. 3. Time variation of global average net surface shortwave radiation, surface air temperature, and precipitation changes for the $5 \mathrm{Tg}$ standard case. The global average precipitation in the control case is $3.0 \mathrm{~mm} /$ day, so the changes in years $2-4$ represent a $9 \%$ global average reduction in precipitation. The precipitation recovers faster than the temperature, but both lag the forcing. For comparison the global average net surface shortwave forcing from a model simulation of the 1991 Mt. Pinatubo eruption (Oman et al., 2005) is shown.

persists for several years, with the global-average value still at $-7 \mathrm{~W} \mathrm{~m}^{-2}$ even five years after the initial smoke injection. This forcing is of opposite sign, but of much greater magnitude than the global average value of $+1.5 \mathrm{~W} \mathrm{~m}^{-2}$ at the surface or $+4 \mathrm{~W} \mathrm{~m}^{-2}$ at the tropopause for a doubling of atmospheric $\mathrm{CO}_{2}$. It also greatly exceeds the maximum global-average surface forcing of $-4 \mathrm{~W} \mathrm{~m}^{-2}$ for the 1991 Mt. Pinatubo volcanic eruption (Kirchner et al., 1999), the largest of the 20th century. The volcanic forcing disappeared with an e-folding time of only $1 \mathrm{yr}$, and during the first year averaged $-3.5 \mathrm{~W} / \mathrm{m}^{2}$ (Fig. 3).

The effects of the smoke cloud on surface temperature are large (Fig. 3). (Stratospheric temperatures are also severely perturbed (Fig. 4)). A global average surface cooling of $-1.25^{\circ} \mathrm{C}$ persists for years, and after a decade the cooling is still $-0.5^{\circ} \mathrm{C}$ (Fig. 3). The temperature changes are largest over land. A map of the temperature change for the Northern Hemisphere summer one year after the smoke injection is shown in Fig. 5. A cooling of several degrees occurs over large areas of North America and Eurasia, including most of the grain-growing regions. As in the case with nuclear winter calculations, large climatic effects would occur in regions far removed from the target areas or the countries involved in the conflict.

Northern Hemisphere winter temperature changes are also large (Fig. 6). Snow feedbacks enhance and prolong the climate response, as seen in areas of snow and sea ice changes

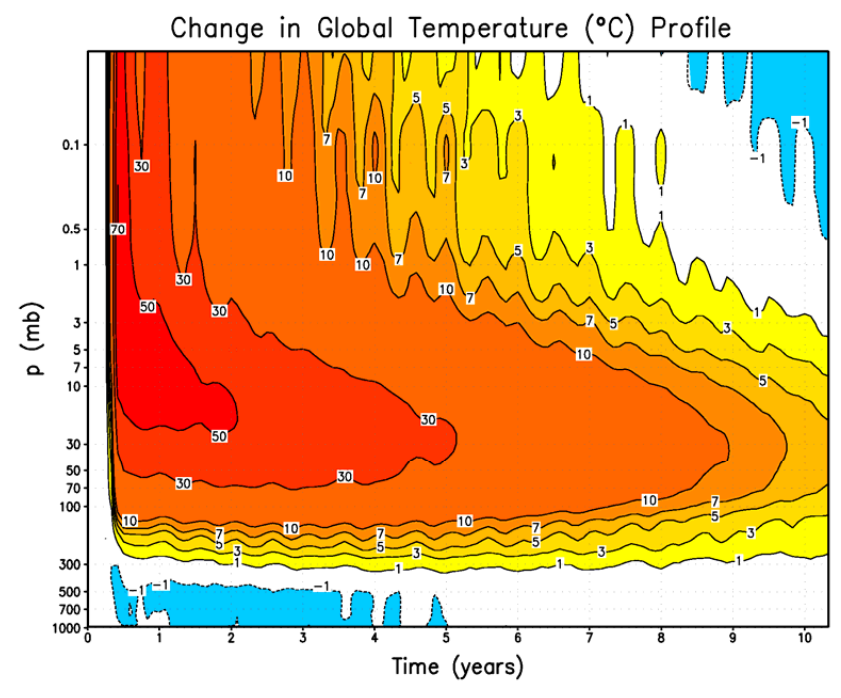

Fig. 4. Change in global average temperature $\left({ }^{\circ} \mathrm{C}\right)$ profile for the $5 \mathrm{Tg}$ standard case from the surface to $0.02 \mathrm{mb}$.

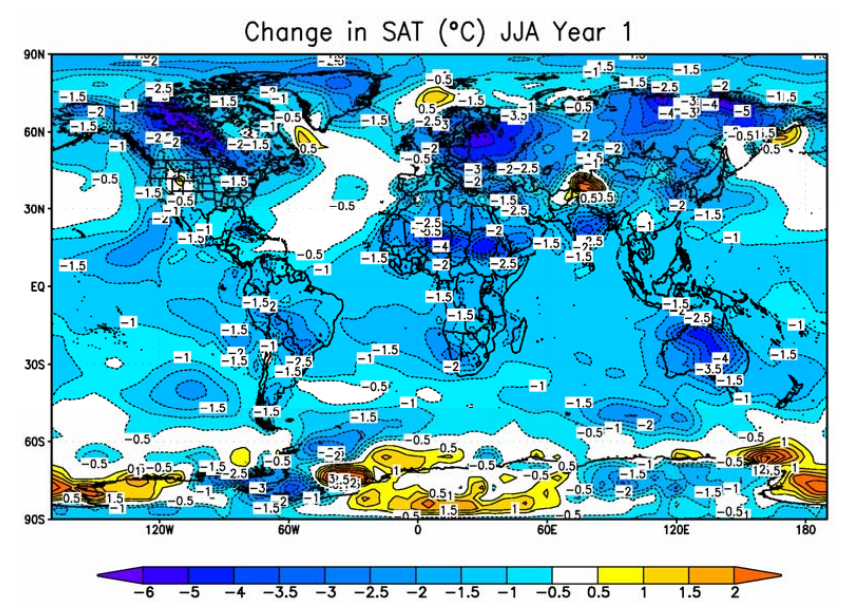

Fig. 5. Surface air temperature changes for the $5 \mathrm{Tg}$ standard case averaged for June, July, and August of the first year following the smoke injection. Effects are largest over land, but there is substantial cooling over tropical oceans, too. The warming over Antarctica is for a small area, is part of normal winter interannual variability, and is not significant.

(Fig. 7). This snow-albedo feedback effect was previously noted by Robock (1984) using an energy-balance model in response to nuclear winter scenarios. In the current simulation, these snow anomalies persist for five years (not shown).

A large Northern Hemisphere winter warming response in northern Eurasia (Fig. 6) also occurred in the first and second winters. This is a well-known response to tropical stratospheric heating that has been observed following large volcanic eruptions (Robock, 2000), and is caused by a forced positive mode of the Arctic Oscillation (Thompson and Wallace, 1998; Stenchikov et al., 2004). The aerosol 

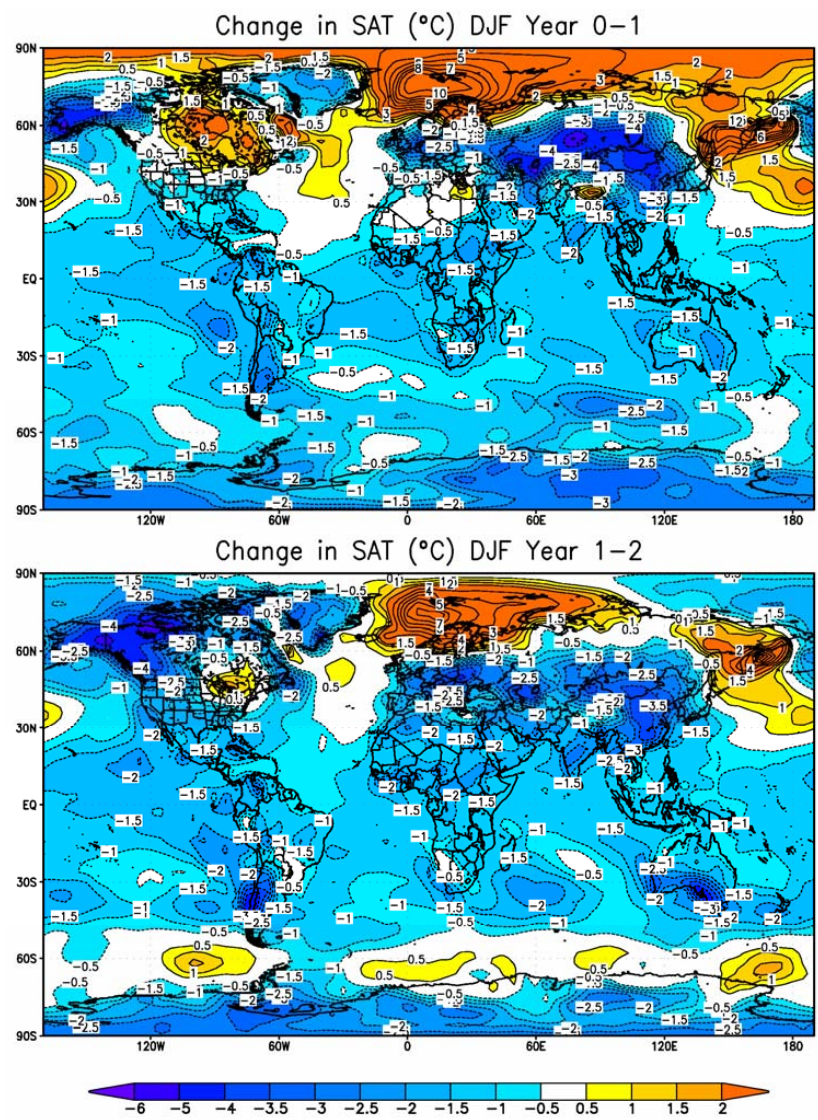

Fig. 6. Surface air temperature changes for the $5 \mathrm{Tg}$ standard case averaged for the first (top) and second (bottom) Northern Hemisphere winters following the smoke injection. While there is large cooling over most land, there is winter warming in northern Eurasia, a well-known response to tropical stratospheric heating that has been observed following large volcanic eruptions (Robock, 2000). The weaker cooling/small warming at $60^{\circ} \mathrm{S}$ in the second winter is a dynamical response in the ocean, caused by weaker surface westerlies in the atmosphere and less vertical mixing in the ocean.

heating in the tropical stratosphere produces an enhanced pole-to-Equator temperature gradient, a stronger jet stream, and the associated tropospheric circulation pattern which advects warm oceanic air over the winter continents.

There is also an area of warming in the second Southern Hemisphere summer at about $60^{\circ} \mathrm{S}$ (Fig. 6). This is not a sea ice feedback, as there are no corresponding sea ice changes (Fig. 7). Rather it is a coupled dynamical-radiative response in the ocean circulation. Significantly weaker westerly winds at the surface produce a weaker oceanic circumpolar current and weaker vertical mixing, reducing the dissipation of solar heating of the surface and allowing less cooling or small warming. This is similar to the mechanism described by Manabe et al. (1991) in coupled atmosphere-ocean climate model experiments with transient increases and decreases of $\mathrm{CO}_{2}$, which also showed small warming in this region with

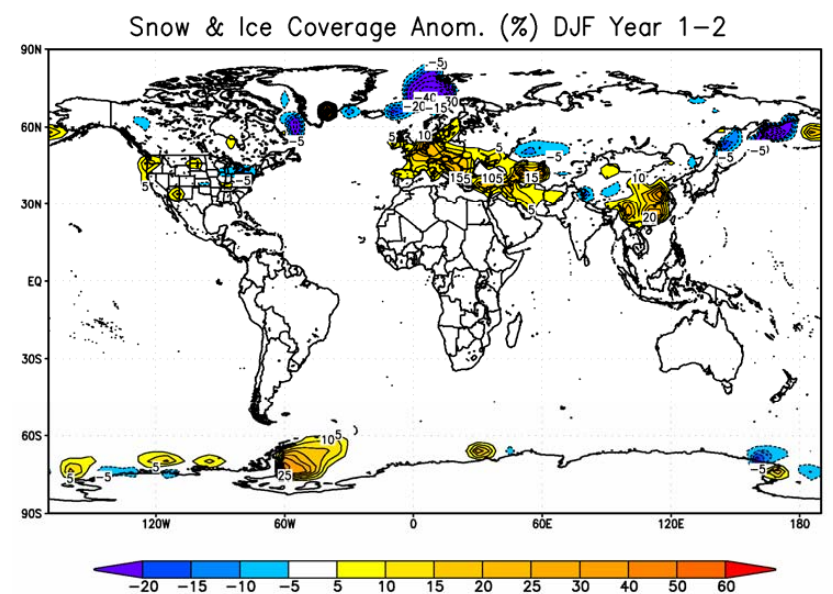

Fig. 7. Change in fractional snow and ice coverage in second Northern Hemisphere winter following smoke injection for the $5 \mathrm{Tg}$ standard case. A $+15 \%$ change means that average coverage for that season, for example, went from $20 \%$ to $35 \%$ or from $0 \%$ to $15 \%$.

reduced $\mathrm{CO}_{2}$. This response is not seen in the first summer (Fig. 6) as radiative effects dominate, but is also seen in the next two Southern Hemisphere summers (not shown).

As a result of the cooling of the Earth's surface, evapotranspiration is reduced and the global hydrological cycle is weakened. The resulting global precipitation is reduced by about $10 \%$ (Fig. 3). Figure 8 shows maps of precipitation change for the Northern Hemisphere summer one year after the smoke injection. Most of the precipitation change is in the Intertropical Convergence Zone, as observed after the 1991 Pinatubo eruption (Spencer et al., 1998), but large areas of continents show substantial changes in their normal seasonal totals, including large reductions of the Asian summer monsoon. Interestingly, there seems to be an enhancement of precipitation over the Sahel region of Africa, which can also be interpreted as weakening of the Hadley Cell circulation.

Ghan et al. (1988), in a nuclear winter study with much larger forcing, found a much larger impact on precipitation, because heating by nuclear smoke of the upper troposphere made the troposphere much more stable, but they only ran their simulations for 30 days. Our simulations, which for the first time allow smoke lofting into the mid and upper stratosphere, remove the smoke from the upper troposphere quickly, and do not produce this response. Robock et al. (2007), in a full nuclear winter simulation with our current model, produced similar lofting, and showed that all previous studies, such as Ghan et al. (1988), were limited by computer modeling capabilities of the time.

The greatest volcanic eruption of the past 500 years, the 1815 Tambora eruption in Indonesia, resulted in a "Year Without a Summer" in 1816 in the Northern Hemisphere, in which killing frosts disrupted agriculture every month of the summer in New England and led to significant emigration 

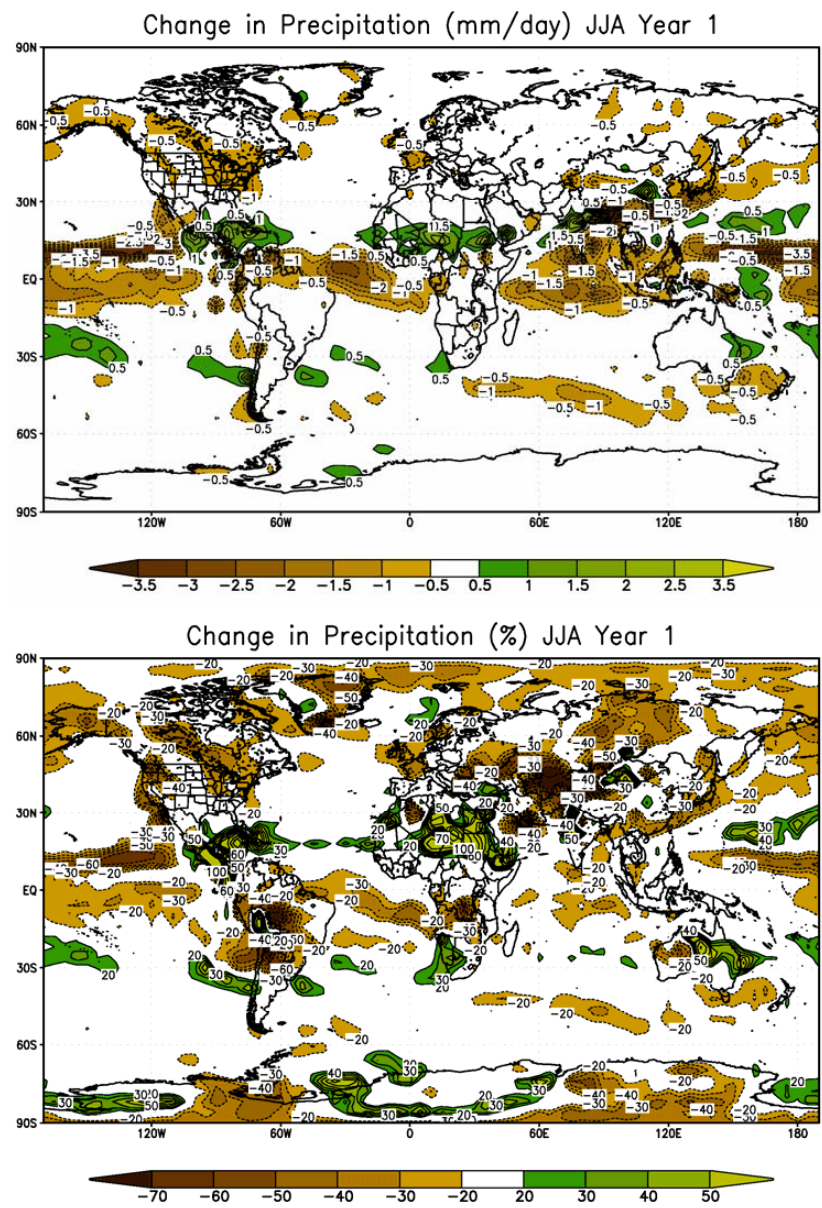

Fig. 8. Precipitation changes in response to the $5 \mathrm{Tg}$ standard case averaged for June, July, and August of the first year following the smoke injection. Top panel shows absolute amount of precipitation change (mm/day), while bottom panel shows \% change.

(Stommel and Stommel, 1983). The weather was so cold and wet that summer in Europe that a widespread harvest failure occurred, resulting in famines and economic collapse (Post, 1970). But that climatic disruption only lasted for about one year. Because the black carbon aerosols in the current simulation are lofted into the upper stratosphere where their residence time is close to a decade, the climatic effects of the $5 \mathrm{Tg}$ case are significantly greater and more persistent than those following the Tambora eruption (Fig. 3). Volcanic ash (large particles of crustal material, also called tephra) and smaller sulfate aerosols both have a much higher single scatter albedo than the smoke from nuclear fires, so absorb much less radiation and exhibit little lofting. Moreover, as we have learned from recent climate model simulations of the effects of volcanic eruptions on oceanic temperature and heat content (Delworth et al., 2005), the climatic impact of such a disruption can persist for more than a century in the ocean. The cooling in the decade following our $5 \mathrm{Tg}$ injection is almost twice as large as the global warming of the past century
GISS Global Average Temperature Anomaly + $5 \mathrm{Tg}$ in 2006

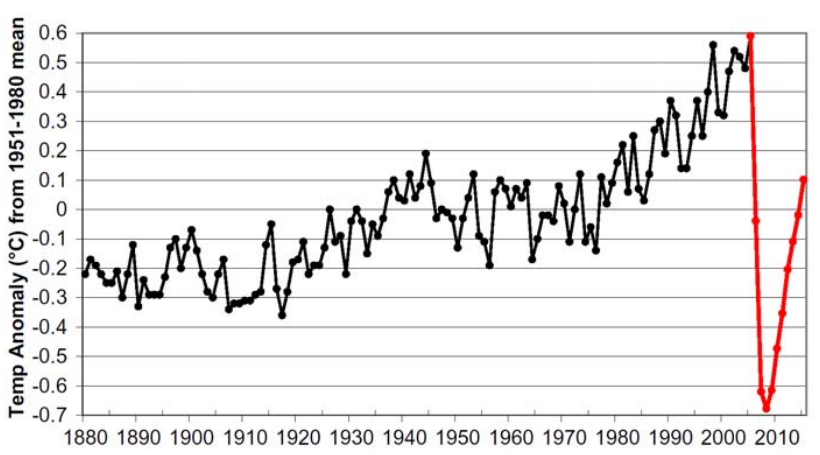

Fig. 9. Global average surface air temperature change from the 5 $\mathrm{Tg}$ standard case (red) in the context of the climate change of the past 125 years. Observations are from the GISS analysis (Hansen et al., 2001, updated at http://data.giss.nasa.gov/gistemp/2005/).

(about $0.7^{\circ} \mathrm{C}$ ) (Fig. 9) and would lead to temperatures cooler than the pre-industrial Little Ice Age (Fig. 10).

\section{Impacts}

There would be many impacts on humans of the direct effects of the weapons used in our scenario (Toon et al., 2007a), including from blast, fires, and radioactivity. Such a regional scale nuclear conflict could produce direct fatalities comparable to all of those worldwide in World War II. But the results presented here indicate that there would also be important indirect effects.

Agriculture would be affected by many factors, including temperature changes, precipitation changes, and changes in insolation (e.g., Robock et al., 1993; Maytín et al., 1995). As an example, Fig. 11 shows changes in the length of the freeze-free growing season for the first full growing seasons in the Northern and Southern Hemispheres. Such large reductions in growing season may completely eliminate crops that have insufficient time to reach maturity. These reductions continue for several years. Also, global ozone loss is likely (Toon et al., 2007a), with effects on downward ultraviolet radiation (Vogelmann et al., 1992). Further analysis of these and other effects, which is beyond the scope of this paper, is needed.

\section{Uncertainties}

The calculations presented here are the first ever of the effects of black carbon from nuclear conflicts with a coupled atmosphere-ocean general circulation model, presumably the most complete and accurate representation of our understanding of the climate system. Nevertheless the results depend on the fidelity of the climate model we used and 


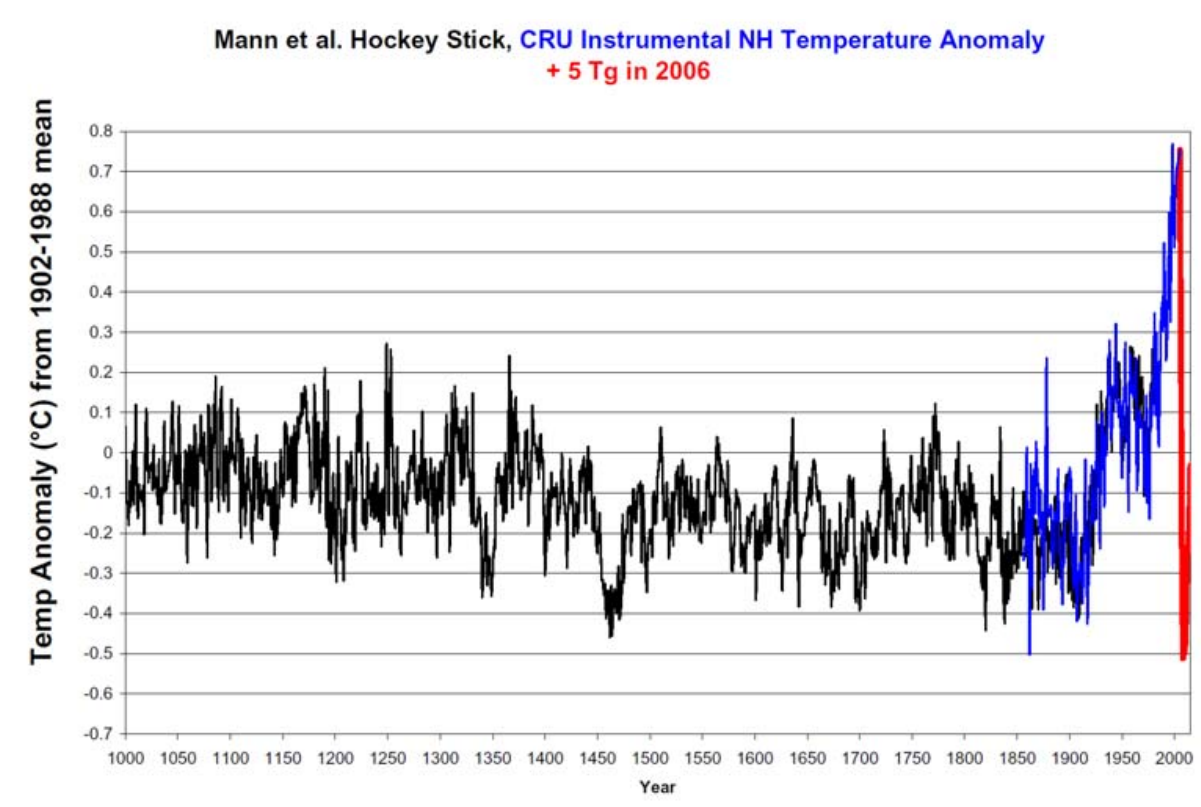

Fig. 10. Northern Hemisphere average surface air temperature change from $5 \mathrm{Tg}$ standard case (red) in the context of the climate change of the past 1000 years. Black curve is from Mann et al. (1999), and the blue curve is from the latest data from the Climatic Research Unit website (http://www.cru.uea.ac.uk/cru/data/temperature/).
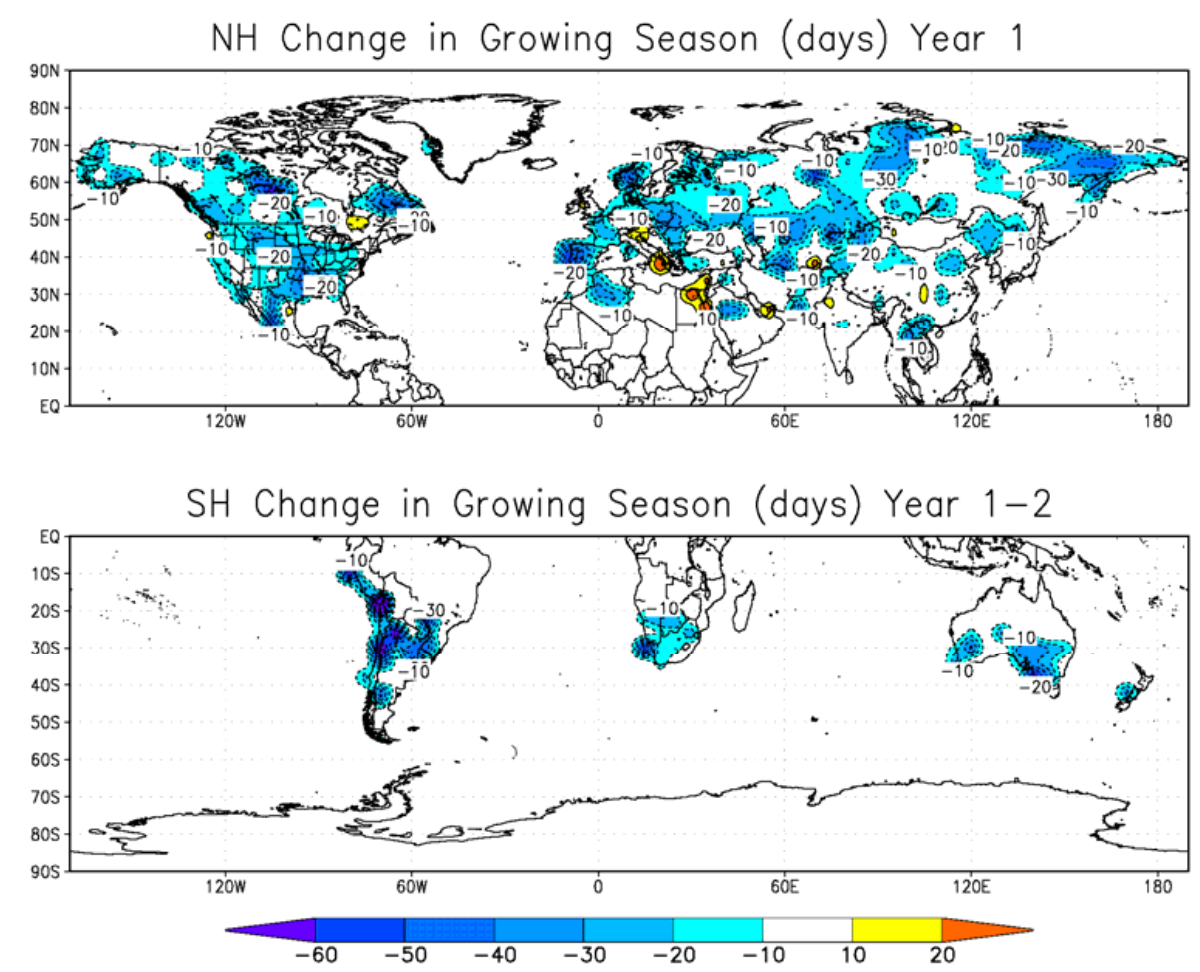

Fig. 11. Change in growing season (period with freeze-free days) in the first year following the $5 \mathrm{Tg}$ standard case smoke injection.

on the assumptions we made. The climate model has been extensively evaluated by our own volcanic cloud simulations (Oman et al., 2005, 2006) and in international intercompar- isons as part of the Fourth Assessment of the Intergovernmental Panel on Climate Change (e.g., Miller et al., 2006; Stenchikov et al., 2006). This model has a climate sensitivity 
in the middle of the range of other models and performs at a level equal to other state-of-the-art models.

We first conducted the entire set of unperturbed climate and $5 \mathrm{Tg}$ perturbations with a version of ModelE coupled to an ocean mixed-layer (slab) model, using the so-called "Q-flux" approach, the same version used in our volcano experiments. The results were very similar to those discussed above, except that the initial cooling in the first year over the oceans was slower, because the ocean general circulation model has thinner ocean layers at the surface that can respond more quickly than did the slab model, but then the maximum global average cooling was a little larger in the slab model (maximum anomaly of $-1.5^{\circ} \mathrm{C}$ in years $3-4$ ) and recovered more slowly (anomaly of $-0.75^{\circ} \mathrm{C}$ after 10 years) because circulation responses in the ocean general circulation model acted to advect away some of the signal. Because both versions of the model gave similar results, as expected, we have more confidence in them. Nevertheless, the experiments should be repeated with other climate models to examine how dependent the results are on the model used.

We used the default values of optical properties for black carbon in the climate model, but smoke from burning cities might be a mixture of black carbon and other material that would be more reflective or with a different size distribution. We assumed that the resulting material would be initially emplaced in the upper troposphere, but this may be conservative as observations show direct stratospheric injections of smoke from intense Canadian and Australian forest fires (Fromm et al., 2003, 2005, 2006).

We conducted experiments with the mixed-layer version of the model, placing the aerosols in the upper troposphere and lower stratosphere, and the results were very similar to those just discussed for an upper tropospheric simulation, with the aerosols having a slightly longer residence time in the latter case. In both cases, the aerosols are lofted to the upper stratosphere with little removal. We also placed the aerosols in a zonal band at $30^{\circ} \mathrm{N}$ in the upper troposphere and lower stratosphere rather than one grid box, which resulted in slightly less lofting due to the reduced initial heating, but the lifetime was still longer than in our standard case in which the aerosols were placed in the upper troposphere. When we placed the aerosols in the lower troposphere (907$765 \mathrm{mb}$ ), about half of the aerosols were removed within 15 days, and the other half were lofted into the stratosphere. Table 1 lists these different runs and the resulting aerosol lifetimes are shown in Fig. 12.

The relatively coarse horizontal resolution used in our atmospheric model $\left(4^{\circ} \times 5^{\circ}\right.$ latitude-longitude) may not be adequate to simulate stratospheric lofting of the aerosols, as actual atmospheric convection occurs on smaller spatial scales. We are currently conducting simulations with a much higher resolution regional climate model to test the dependence on scale, but those experiments are beyond the scope of this paper.

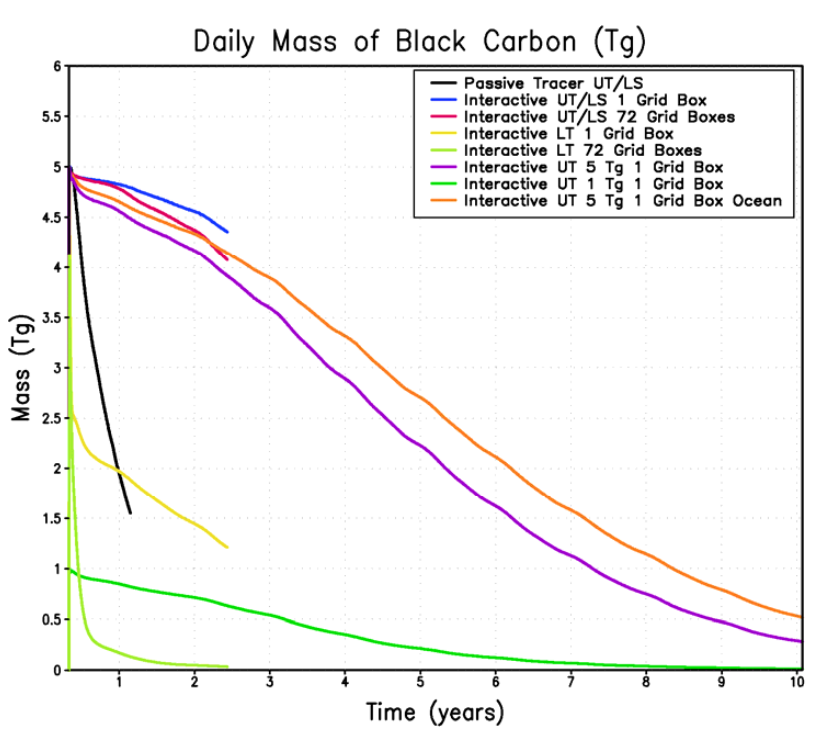

Fig. 12. Comparative black carbon aerosol loading for different test cases mentioned in the text and Table 1 with the mixed-layer climate model. UT is upper troposphere, LT is lower troposphere, and LS is lower stratosphere. The purple line labeled "Interactive UT 5 Tg" is for the climate model with the mixed-layer ocean, and the one labeled "Ocean" is for the standard run presented in this paper with the full ocean general circulation model.

While Ledley and Thompson (1986) suggested that soot falling on sea ice would increase the albedo and negate some of the cooling from a massive atmospheric aerosol loading, Vogelmann et al. (1988) used an energy-balance climate model (Robock, 1984) and showed that this effect would only be important with enough solar insolation to make snow and ice albedo important. By the time the atmosphere was clear enough, Vogelmann et al. showed that clean snow would have fallen on the dirty snow, making the effect small. This feedback was not incorporated in the runs presented here, but as ModelE has the capacity to investigate this feedback (Hansen and Nazarenko, 2004), the strength of this effect should be investigated in further studies with this comprehensive model.

The black carbon particles in our model have an effective radius of $0.1 \mu \mathrm{m}$, but the radiative effects of the aerosols depend on their size. Reid (2005) clearly shows that smoke from biomass fires has very small particles, with a mean diameter of $0.1-0.2 \mu \mathrm{m}$, but additional experiments should be conducted to test the dependence of the results on the model assumptions.

Our model does not account for coagulation of the black carbon particles, and subsequent reduction in their effects on radiation and their lifetime. However, we find that the particle density once lofted is only a few tens of particles $/ \mathrm{cm}^{3}$. Coagulation at these densities will reduce the concentration by a factor of $e$ in about one year (Toon et al., 2001), so only small reductions in concentration due to coagulation 
Table 1. Description of test cases for the model runs. The results for the upper troposphere (UT) 5 Tg (Standard) case are presented in detail in this paper. The UT run with the mixed-layer ocean, discussed in the text, had the same setup as the UT (Standard), except the control run was only $15 \mathrm{yr}$. The global aerosol loading for all cases is shown in Fig. 12. The smoke in the passive run was not radiatively active as in all the other runs.

\begin{tabular}{llllll}
\hline Run & Ensemble members & Duration (yr) & Mass (Tg) & $\begin{array}{c}\text { Smoke injection } \\
\text { Layer (mb) }\end{array}$ & Location \\
\hline Control & 1 & 30 & 0 & $\mathrm{~N} / \mathrm{A}$ & $\mathrm{N} / \mathrm{A}$ \\
Passive & 3 & 10 & 5 (passive) & $170-100$ & $30^{\circ} \mathrm{N}, 70^{\circ} \mathrm{E}$ \\
UT/LS & 3 & 10 & 5 & $170-100$ & $30^{\circ} \mathrm{N}, 70^{\circ} \mathrm{E}$ \\
UT/LS Band & 3 & 10 & 5 & $170-100$ & $30^{\circ} \mathrm{N}$ band \\
UT (Standard) & 3 & 10 & 5 & $300-150$ & $30^{\circ} \mathrm{N}, 70^{\circ} \mathrm{E}$ \\
UT 1 Tg & 3 & 10 & 1 & $300-150$ & $30^{\circ} \mathrm{N}, 70^{\circ} \mathrm{E}$ \\
LT & 3 & 10 & 5 & $907-765$ & $30^{\circ} \mathrm{N}, 70^{\circ} \mathrm{E}$ \\
LT Band & 3 & 10 & 5 & $907-765$ & $30^{\circ} \mathrm{N} \mathrm{band}$ \\
\hline
\end{tabular}

are expected. Moreover, soot aerosols tend to coagulate to chain-shaped and fluffy particles with fall velocities that are low relative to equal mass spheres. The optical properties of non-spherical carbon particles do not change significantly with particle size, as do those of spherical particles (Nelson, 1989). Our results do not account for possible reduction in smoke absorption due to photochemical processing in the stratosphere (Toon et al., 2007a), which may reduce the overall lifetime of the soot.

We also conducted simulations with an injection of $1 \mathrm{Tg}$ of black carbon into the upper troposphere, to investigate the effects of a smaller number of nuclear explosions, or different assumptions about smoke emissions and smoke properties. The global temperature and precipitation perturbations after one year for the $1 \mathrm{Tg}$ case were about $1 / 5$ of those of the $5 \mathrm{Tg}$ case. The smoke was not lofted quite as high in the stratosphere, but the e-folding lifetime of $3.6 \mathrm{yr}$ was still much longer than that for volcanic aerosols (compare curves in Figs. 3 and 12).

\section{Policy implications}

People are congregating in the world's great urban centers, creating megacities with populations exceeding 10 million individuals. There are at least eight countries with substantial nuclear weapons inventories, and 40 countries control sufficient amounts of uranium or plutonium to manufacture nuclear explosives (Toon et al., 2007a). Remarkably, the estimated quantities of smoke generated by attacks totaling little more than one megaton of nuclear explosives could lead to global climate anomalies exceeding any changes experienced in recorded history. The current global arsenal is about 5000 megatons.

The major policy implication of nuclear winter was that a full-scale nuclear attack would produce climatic effects which would so disrupt the food supply that it would be sui- cide for the attacking country (Robock, 1989) and would also impact non-combatant countries. The subsequent end of the arms race and reduction of superpower tensions can be traced back to the world being forced to confront both the direct and indirect consequences of the use of nuclear weapons by the public policy debate in response to nuclear winter theory. The Soviet Union did not end until five years after nuclear warhead numbers began to drop steeply, and the end of the Soviet Union did not alter the slope of the decline. While significant reductions of American and Russian nuclear arsenals followed, each country still retains enough weapons to produce a nuclear winter (Robock et al., 2007). We find that several other countries now possess enough nuclear weapons to not only severely damage themselves and others directly by a regional nuclear war, but also to damage the rest of the world through significant global climate changes, as documented here and by Toon et al. (2007a). The results in this paper need to be tested with other climate models, and the detailed consequences on agriculture, water supply, global trade, communications, travel, air pollution, and many more potential human impacts need further study. Each of these potential hazards deserves careful analysis by governments advised by a broad section of the scientific community, as discussed in more detail by Toon et al. (2007b).

Acknowledgements. A. Robock, G. L. Stenchikov, and L. Oman were supported by U.S. National Science Foundation grants ATM-0313592 and ATM-0351280.

Edited by: W. Conant

\section{References}

Aleksandrov, V. V. and Stenchikov, G. L.: On the modeling of the climatic consequences of the nuclear war, Proc. Applied Math, Computing Centre, USSR Academy of Sciences, Moscow, 21 pp., 1983. 
Covey, C., Thompson, S., and Schneider, S. H.: Global atmospheric effects of massive smoke injections from a nuclear war: results from general circulation model simulations, Nature, 308, 21-25, 1984.

Crutzen, P. J. and Birks, J. W.: The atmosphere after a nuclear war: Twilight at noon, Ambio, 11, 114-125, 1982.

Delworth, T. L., Ramaswamy, V., and Stenchikov, G. L.: The impact of aerosols on simulated ocean temperature and heat content in the 20th century, Geophys. Res. Lett., 32, L24709, doi:10.1029/2005GL024457, 2005.

Fromm, M. D. and Servranckx, R.: Transport of forest fire smoke above the tropopause by supercell convection, Geophys. Res. Lett., 30(10), 1542, doi:10.1029/2002GL016820, 2003.

Fromm, M., Bevilacqua, R., Servranckx, R., Rosen, J., Thayer, J. P., Herman, J., and Larko D.: Pyro-cumulonimbus injection of smoke to the stratosphere: Observations and impact of a super blowup in northwestern Canada on 3-4 August 1998, J. Geophys. Res., 110, D08205, doi:10.1029/2004JD005350, 2005.

Fromm, M., Tupper, A., Rosenfeld, D., Servranckx, R., and McRae, R.: Violent pyro-convective storm devastates Australias capital and pollutes the stratosphere, Geophys. Res. Lett., 33, L05815, doi:10.1029/2005GL025161, 2006.

Ghan, S. J.; MacCracken, M. C., and Walton, J. J.: Climatic response to large atmospheric smoke injections: Sensitivity studies with a tropospheric general circulation model, J. Geophys. Res., 93, 8315-8337, 1988.

Hansen, J. E., Ruedy, R., Sato, M., Imhoff, M., Lawrence, W., Easterling, D., Peterson, T., and Karl, T.: A closer look at United States and global surface temperature change, J. Geophys. Res., 106, 23 947-23 963, doi:10.1029/2001JD000354, 2001.

Hansen, J. and Nazarenko, L.: Soot climate forcing via snow and ice albedos, Proc. Natl. Acad. Sci., 101, 423-428, doi:10.1073/pnas.2237157100, 2004.

Harwell, M. A. and Hutchinson, T. C. (Eds.): Environmental Consequences of Nuclear War, SCOPE 28. Volume II, Ecological and Agricultural Effects, John Wiley \& Sons, New York, 1986.

Kirchner, I., Stenchikov, G. L., Graf, H.-F., Robock, A., and Antuña, J. C.: Climate model simulation of winter warming and summer cooling following the 1991 Mount Pinatubo volcanic eruption, J. Geophys. Res., 104, 19 039-19 055, 1999.

Koch, D., Schmidt, G. A., and Field, C. V.: Sulfur, sea salt, and radionuclide aerosols in GISS ModelE, J. Geophys. Res., 111, D06206, doi:10.1029/2004JD005550, 2006.

Ledley, T. S. and Thompson, S. L.: Potential effect of nuclear war smokefall on sea ice, Climatic Change, 8, 155-171, 1986.

Malone, R. C., Auer, L. H., Glatzmaier, G. A., Wood, M. C., and Toon, O. B.: Nuclear winter: Three-dimensional simulations including interactive transport, scavenging, and solar heating of smoke, J. Geophys. Res., 91, 1039-1054, 1986.

Manabe, S., Stouffer, R. J., Spelman, M. J., and Bryan, K.: Transient responses of a coupled ocean-atmosphere model to gradual changes of atmospheric $\mathrm{CO}_{2}$. Part I. Annual mean response, J. Climate, 4, 785-818, 1991.

Mann, M. E., Bradley, R. S., and Hughes, M. K.: Northern Hemisphere temperatures during the past millennium: Inferences, uncertainties, and limitations, Geophys. Res. Lett., 26, 759-762, 1999.

Maytín, C. E., Acevedo, M., Jaimez, R., Andressen, R., Harwell, M. A., Robock, A., and Azócar, A.: Potential effects of global cli- matic change on the phenology and yield of maize in Venezuela, Climatic Change, 29, 189-211, 1995.

Miller, R. L., Schmidt, G. A., and Shindell, D.: Forced annular variations in the 20th century Intergovernmental Panel on Climate Change Fourth Assessment Report models, J. Geophys. Res., 111, D18101, doi:10.1029/2005JD006323, 2006.

Nelson, J.: Fractality of sooty smoke: Implications for the severity of nuclear winter, Nature, 339, 611-613, 1989.

Oman, L., Robock, A., Stenchikov, G., Schmidt, G. A., and Ruedy, R.: Climatic response to high latitude volcanic eruptions, J. Geophys. Res., 110, D13103, doi:10.1029/2004JD005487, 2005.

Oman, L., Robock, A., Stenchikov, G. L., Thordarson, T., Koch, D., Shindell, D. T., and Gao, C.: Modeling the distribution of the volcanic aerosol cloud from the 1783-1784 Laki eruption, J. Geophys. Res., 111, D12209, doi:10.1029/2005JD006899, 2006.

Pittock, A. B., Ackerman, T. P., Crutzen, P. J., MacCracken, M. C., Shapiro, C. S., and Turco, R. P. (Eds.): Environmental Consequences of Nuclear War, SCOPE 28. Volume I, Physical and Atmospheric Effects, John Wiley \& Sons, New York, 1986.

Post, J. D.: The economic crisis of 1816-1817 and its social and political consequences, J. Econom. His., 30, 248-250, 1970.

Reid, J. S., Koppmann, R., Eck, T. F., and Eleuterio, D. P.: A review of biomass burning emissions part II: Intensive physical properties of biomass burning particles, Atmos. Chem. Phys., 5, 799825, 2005,

http://www.atmos-chem-phys.net/5/799/2005/.

Robock, A.: Snow and ice feedbacks prolong effects of nuclear winter, Nature, 310, 667-670, 1984.

Robock, A.: Policy implications of nuclear winter and ideas for solutions, Ambio, 18, 360-366, 1989.

Robock, A.: Volcanic eruptions and climate, Rev. Geophys., 38, 191-219, 2000.

Robock, A., Turco, R. P., Harwell, M. A., Ackerman, T. P., Andressen, R., Chang, H.-S., and Sivakumar, M. V. K.: Use of general circulation model output in the creation of climate change scenarios for impact analysis, Climatic Change, 23, 293-335, 1993.

Robock, A., Oman, L., and Stenchikov, G. L.: Nuclear winter revisited with a modern climate model and current nuclear arsenals: Still catastrophic consequences J. Geophys. Res., in press, doi:10.1029/2006JD008235, 2007.

Russell, G. L., Miller, J. R., and Rind, D.: A coupled atmosphereocean model for transient climate change, Atmos.-Ocean, 33, 683-730, 1995.

Sagan, C. and Turco, R.: A Path Where No Man Thought - Nuclear Winter and the End of the Arms Race, New York, Random House, 1990.

Schmidt, G. A., Ruedy, R., Hansen, J. E., et al.: Present-day atmospheric simulations using GISS ModelE: Comparison to in situ, satellite, and reanalysis data, J. Climate, 19, 153-192, 2006.

Schneider, S. H. and Thompson, S. L.: Simulating the climatic effects of nuclear war, Nature, 333, 221-227, 1988.

Spencer, R. W., LaFontaine, F. J., DeFelice, T., and Wentz, F. J.: Tropical oceanic precipitation changes after the 1991 Pinatubo eruption, J. Atmos. Sci., 55, 1707-1713, 1998.

Stenchikov, G. L., Kirchner, I., Robock, A., Graf, H.F., Antuña, J. C., Grainger, R. G., Lambert, A., and Thomason, L.: Radiative forcing from the 1991 Mount Pinatubo volcanic eruption, J. Geophys. Res., 103, 13 837-13 857, 1998. 
Stenchikov, G., Hamilton, K., Robock, A., Ramaswamy, V., and Schwarzkopf, M. D.: Arctic Oscillation response to the 1991 Pinatubo eruption in the SKYHI GCM with a realistic Quasi-Biennial Oscillation, J. Geophys. Res., 109, D03112, doi:10.1029/2003JD003699, 2004.

Stenchikov, G., Hamilton, K., Stouffer, R. J., Robock, A., Ramaswamy, V., Santer, B. and Graf, H.-F.: Climate impacts of volcanic eruptions in the IPCC AR4 climate models, J. Geophys. Res., 111, D07107, doi:10.1029/2005JD006286, 2006.

Stommel, H. and Stommel, E., Volcano Weather, the Story of 1816, The Year Without a Summer, Seven Seas Press, Newport, R. I., 177 pp., 1983.

Thompson, D. W. J. and Wallace, J. M.: The Arctic Oscillation signature in the wintertime geopotential height and temperature fields, Geophys. Res. Lett., 25, 1297-1300, 1998.

Toon, O. B. and Farlow, N. H.: Particles above the tropopause: Measurements and models of stratospheric aerosols, meteoric debris, nacreous clouds, and noctilucent clouds, Ann. Rev. Earth Planet. Sci., 9, 19-58, 1981.
Toon, O. B., Turco, R. P., Robock, A., Bardeen, C., Oman, L., and Stenchikov, G. L.: Consequences of regional scale nuclear conflicts and acts of individual nuclear terrorism, Atmos. Chem. Phys., 7, 1973-2002, 2007, http://www.atmos-chem-phys.net/7/1973/2007/.

Toon, O. B., Robock, A., Turco, R. P., Bardeen, C., Oman, L., and Stenchikov, G. L.: Consequences of regional-scale nuclear conflicts, Science, 315, 1224-1225, 2007b.

Turco, R. P., Toon, O. B., Ackerman, T. P., Pollack, J. B., and Sagan, C.: Nuclear winter: Global consequences of multiple nuclear explosions, Science, 222, 1283-1292, 1983.

Turco, R. P., Toon, O. B., Ackerman, T. P., Pollack, J. B., and Sagan, C.: Climate and smoke: An appraisal of Nuclear Winter, Science, 247, 166-176, 1990.

Vogelmann, A. M., Robock, A., and Ellingson, R. G.: Effects of dirty snow in nuclear winter simulations, J. Geophys. Res., 93, 5319-5332, 1988

Vogelmann, A. M., Ackerman, T. P., and Turco, R. P.: Enhancements in biologically effective ultraviolet radiation following volcanic eruptions, Nature, 359, 47-49, doi:10.1038/359047a0, 1992. 